\title{
A Design Method for Rail Profiles in Switch Panel of Turnout Based on the Contact Stress Analysis
}

\author{
Dilai Chen $\mathbb{D}^{1},{ }^{1}$ Gang Shen, ${ }^{2}$ Xin Mao, ${ }^{2}$ and Buchen Chen ${ }^{2}$ \\ ${ }^{1}$ School of Railway Transportation, Shanghai Institute of Technology, Shanghai, China \\ ${ }^{2}$ Railway and Urban Rail Transit Research Institute, Tongji University, Shanghai, China \\ Correspondence should be addressed to Dilai Chen; chendilai@163.com
}

Received 28 July 2019; Revised 2 October 2019; Accepted 8 October 2019; Published 9 October 2020

Academic Editor: Dr Mahdi Mohammadpour

Copyright (c) 2020 Dilai Chen et al. This is an open access article distributed under the Creative Commons Attribution License, which permits unrestricted use, distribution, and reproduction in any medium, provided the original work is properly cited.

Contact stress between wheel and rail is believed to cause damage to the rail. The relationship between the contact stress and the radius of the rail is initially based on the Hertz contact theory. By adjusting its radius, the rail profile is designed with an objective of reducing the maximal contact stress between wheel and rail. The rail profile of turnout is parameterized by defining several control cross sections along the switch. The experiment of dynamic vehicle-turnout interaction is also carried out to investigate the effect of the improved rail profile on the dynamical behavior of the vehicle. The method is then verified through examples using rail profile with a switch width of $20 \mathrm{~mm}$ and LM worn-type tread at the CN60-350-1:12 turnout. The results show that the designed rail has a higher matching degree with the wheel profile. It can reduce the contact stress, improve the wheel-rail contact state, and prolong the service life of the rail without deteriorating the dynamic performance of the vehicle passing through the turnout.

\section{Introduction}

Turnouts are mechanical installations enabling railway trains to be guided from one track to another, which makes them become integral components of the railway infrastructure. When a vehicle passes through the switches at the turnouts, the wheel-rail contact stress and contact geometry also change along with the track width variation. The complex wheel-rail contact conditions at the switches aggravate the wheel-rail contact stresses, wheel and rail wear, and the rolling contact fatigue of rail [1]. Rail grinding technology is an integral part of railway maintenance, which can remove the rail surface defects with accumulated rolling contact fatigue, relieve the adverse wheel and rail wear, reduce the wheel-rail contact stress, and repair rail profile to prolong the service life of the rail $[2,3]$.

The optimization design of wheel and rail profiles is crucial for the wheel-rail system performance, and relevant issues were discussed in many previous literatures [4-14]. The geometry characteristic of the wheel and rail profile is closely related to the vehicle operational safety, dynamic performance, and the service life of wheel and rail. A reasonable improvement of the wheel-rail contact conditions is able to reduce wheel-rail contact stress and therefore prolong the rail service life. Thus, Shevtsov et al. [4] and Shen and Zhong [5] proposed the optimization design of the wheel tread surface based on the rolling radius difference function. The obtained wheel tread surface proved to be effective in reducing the wheel and rail wear without deteriorating the dynamic performance. Cui et al. [6] put forward an optimization design method of the wheel profile, which regarded the minimization of the normal dynamic gap between the wheel and rail as the optimization goal. This approach took the modified sequential quadratic programming (SQP) as an iterative method for constrained nonlinear optimization, however, which turned out to be quite time-consuming. Smallwood et al. [7] adopted an optimization method for minimizing the wheel-rail contact stress. By optimizing the rail profile of the curved outer track, the maximum wheel-rail contact stress was reduced by about $50 \%$. Besides, it was reported that the contact stress between the wheel and rail had a large impact on the 
initiation of rolling contact fatigue cracks of the curved outer rail. Mao and Shen [8] proposed a reverse design method for the rail grinding profile, which used the rolling radius difference or contact angle difference as the objective function of optimization. The optimized profile was able to reduce wheel-rail contact stress and make the distribution of contact points more uniform, but it was not suitable for turnout design. Magel and Kalousek [9] proposed the criteria for rail profile design from five standpoints, namely, antiwear, antifatigue, inhibition of wave corrugation development, optimal stability, and noise reduction. After grinding design, the rail profile matched well with the wheel profile, the wheel-rail contact stress decreased obviously, and the service lives of the wheel and rail were increased. Since the contact conditions between the wheel and rail at the railway switches are quite complicated, few optimization studies have been conducted for the switches. In order to improve the dynamic performance of turnout crossings, Wan [10] proposed a numerical method to optimize the shape of the rail to reduce rolling contact fatigue and wear, but its shortcoming is that this method needs lots of time for computation. Wang et al. [11] derived an optimized rail profile at the railway switches by SQP using the rolling radius difference function as the objective function of optimization. The optimized profile could effectively improve the geometry characteristic of wheel-rail contact and enhance the operational stability of railway switch components, but their work only included optimizing a section profile in switch panel. Pålsson et al. [12] introduced the multiobjective minimal optimization method for the energy dissipation based on the contact pressure and wheel-rail contact estimations. The genetic optimization algorithm was used to design the rail profile at the railway switches and to improve the dynamic performance of the vehicle passing the turnout. However, this method increased the vertical load on the rail at the switches. Bugarín et al. [13] suggested optimizing the impact load at the turnout by widening the track gauge at the turnout switches. As a result, an appropriate widening of the track gauge improved the dynamic action of the vehicle passing through the turnout and reduced the rolling contact fatigue and wear at the turnout. Oswald [14] proposed a design method for the geometric shape of the turnout, and it is possible to reduce the forces created by wheel-rail contact up to $30 \%$. With the use of kinematic gauge optimization, further reduction of the forces in a turnout by up to $50 \%$ was allowed.

Unfortunately, insulated rail joints and switch with gaps cause stiffness discontinuity and stress singularity in rail sections, which significantly increases the contact force and causes harmful vibrations of the vehicle and the track system [15]. There is a problem that the rolling contact behavior between wheels and rails in the switch panel is different from that in the tangent track rail system due to the discontinuity of rails. Recently Zong and Dhanasekar [16] used the FE code Abaqus/Standard to analyze the wheel-rail contact and then provided an idea of simplifying the design of the IRJs consisting of only two pieces of insulated rails embedded into a concrete sleeper. But it takes $3.5 \mathrm{~h}$ to calculate one time. Chen and Chen [17] assumed that the rail and the IRJ are connected and discussed the Hertz and FEM model. The distributions of contact pressure significantly deviate from HCT and Carter's results as the wheel/rail contact point is near the IRJ. $\mathrm{Lu}$ [18] conducted a comparative analysis of normal pressure of FEM and Hertzian theory, indicating that the maximum pressure from FEM results is slightly less than that in Hertz's theory and the contact area from FEM results in the longitudinal direction is slightly larger than that with Hertz's theory. But the calculation time could be more than ten times longer. Chen and Kuang [19] and Nirmal Kumar Mandal [20] carried out a 3D finite element analysis on an insulated rail joint to investigate the effect of rail joint parameters on the contact pressure distribution and contact stress variation near wheel-rail contact zones. They indicated that due to nonlinearity, the traditional Hertz contact theory (HCT) was no longer sufficient to predict stress contours near insulated rail joints. Mandal [21] used an FE model based on the modified HCT to determine the stress distribution on the railhead in the vicinity of end post. However, turnout is different from insulating rail joints; in the most control cross section, the wheel-rail contact point does not occur in the points of singularities (the point of switch rail working and nonworking side). Wiest and Kassa [22] assessed four models for wheel-rail rolling contact at a given cross section in the crossing panel of a selected turnout design, and it is found that the contact pressure distributions calculated using Hertz and CONTACT correlate well with those results obtained from the finite element method as long as no plasticization of the material occurs. Li et al. [23] carried out a comparative analysis of normal pressure about No.18 switch panel using Hertz, simi-Hertz, and Kalker three-dimensional non-Hertz rolling contact theory. In their study, the difference between the maximum contact area and the maximum contact stress was less than $10 \%$. In this paper, the wheel-rail contact stress distributions of No. 12 turnout under Hertz and non-Hertz theories are compared and analyzed.

The optimization design of rail grinding profile can effectively improve the geometry characteristic of the wheelrail contact, reduce the contact stress and alleviate dynamic interaction, and increase the rail service life. The wheel-rail contact stress has a significant impact on the generation and development of rolling contact fatigue cracks. Excessive contact stress will cause huge damage to the rail. The matching degree of wheel and rail profile directly influences the magnitude of contact stress. Reducing the wheel-rail contact stress and minimizing wheel and rail damage are the critical tasks in wheel and rail profile design. In this study, an optimization design method of rail profile in a switch panel is proposed using the wheel-rail contact stress as the objective function of optimization. On this basis, a reverse design method of rail profile from the rail radius is established. Since the rail profile of the switch panel varies continuously along the longitudinal direction, several control sections are selected for optimization design, and other sections are obtained through interpolation [10]. This method can ensure the smoothness of the optimized rail profile. An improved profile of the control section of No. 12 turnout is obtained by using the proposed method. An 
example is given below to demonstrate the advantages of the method.

\section{An Optimization Model of the Rail Profile}

\subsection{Wheel-Rail Normal Contact Theory}

2.1.1. The Hertz Contact Theory. The Hertz contact theory is used as the theoretical basis for the contact stress computation. According to the classical Hertz contact theory, the wheel-rail contact is simplified as an infinite elastic half-space. The wheel and rail deformation at the contact point is negligible, and the wheel and rail are two elastic cylinders that are mutually perpendicular to each other. The contact surface between the two is elliptical, with the maximum stress $p_{0}$ appearing at the center of the elliptical contact spot [24]:

$$
p_{0}=\frac{3 P}{2 \pi a b}
$$

where $P$ is the normal force applied to the elliptical contact spot, while $a$ and $b$ are the major and minor semiaxes of the elliptical contact spot, respectively.

The above values $a$ and $b$ are calculated as follows:

$$
\begin{aligned}
& a=m\left[\frac{3}{2} \times \frac{G^{*} P}{2(A+B)}\right]^{1 / 3} ; \\
& b=n\left[\frac{3}{2} \times \frac{G^{*} P}{2(A+B)}\right]^{1 / 3},
\end{aligned}
$$

where $m$ and $n$ are the coefficients for computing the wheelrail contact via the Hertz contact theory and $A$ and $B$ are the geometrical factors.

The above value of $G^{*}$ is calculated as follows:

$$
G^{*}=\frac{1-v_{1}^{2}}{E_{1}}+\frac{1-v_{2}^{2}}{E_{2}},
$$

where $E_{1}$ and $E_{2}$ are the elastic moduli of the wheel and rail material, respectively. $\nu_{1}$ and $\nu_{2}$ are Poisson's ratio of the wheel and rail material, respectively.

Geometrical factors $A$ and $B$ are obtained as follows:

$$
\begin{aligned}
& A+B=\frac{1}{2}\left(\frac{1}{R_{1}}+\frac{1}{R_{2}}+\frac{1}{R_{3}}\right) ; \\
& A-B=\frac{1}{2}\left(\frac{1}{R_{1}}+\frac{1}{R_{2}}-\frac{1}{R_{3}}\right),
\end{aligned}
$$

where $R_{1}$ is the wheel rolling radius, $R_{2}$ is the profile radius of the wheel tread cross section, and $R_{3}$ is the profile radius of the rail cross section.

According to the Hertz contact theory, changes in radius of wheel and rail profile directly influence the magnitude of the indirect wheel-rail contact stress.

\subsubsection{Kalker Three-Dimensional Non-Hertz Rolling Contact} Theory. In order to analyze the contact between nonstandard wheel-rail profiles more accurately, Kalker [24] proposed a three-dimensional non-Hertz rolling contact theory.
Based on the assumption of elastic half-space, combined with geometric equation, constitutive equation, boundary conditions of force and displacement, and Gauss integral, the principle of complementary energy of rolling contact is transformed into the expression of surface mechanics. The theory is the most perfect method to solve the rolling contact problem between wheel and rail. On the premise of satisfying the basic assumptions, the developed numerical program CONTACT can be used to accurately calculate contact information such as contact area and contact stress distribution under arbitrary wheel-rail profile. However, the timeconsuming and inefficient calculation of CONTACT is not suitable for solving every time step of vehicle-track system dynamics. Therefore, its calculation results are usually used to verify the accuracy of other approximate calculation methods, which is known as the "golden standard" of wheelrail contact. The contact problem is converted to a mathematical minimization of the constrained function and implemented in MATLAB.

The minimization function of the normal problem is given by

$$
\begin{aligned}
& \min F=\frac{1}{2} \sum_{i=1}^{N} \sum_{j=1}^{N} p_{i} A_{i 3 j 3} p_{j}+\sum_{i=1}^{N} h_{i} p_{i} \\
& \text { subject to } p_{0}=\Delta x \Delta y \sum_{i=1}^{N} p_{i},
\end{aligned}
$$

where $N$ is the number of elements in the potential area, $p_{i}$ and $p_{j}$ are the pressure of the $i$ th and $j$ th elements, $h_{i}$ is the undeformed distance, and $\Delta x$ and $\Delta y$ are the dimensions of the element.

2.1.3. Results and Discussion. A dynamic load generates due to the motion of the wheel over the roughness, and this varying normal force is normally obtained from a wheeltrack interaction model. However, the wheel-track interaction is not addressed here, and a constant normal force is initially used [22].

In this section, the results from Hertz and three-dimensional non-Hertz methods are compared and discussed. The wheel-rail contact relationship between LM wheel tread and a switch point width of $20 \mathrm{~mm}$ rail profile of No. 12 turnout is analyzed. The axle load is 17 tons. The calculated wheel-rail contact stress distribution results based on Hertz and non-Hertz contact theories are shown in Figures 1-4. The corresponding wheelset transverse displacement is $0 \mathrm{~mm},-3 \mathrm{~mm},-6 \mathrm{~mm}$, and $-9 \mathrm{~mm}$ respectively. It can be seen that the contact area of wheel and rail calculated by Hertz contact theory is ellipse under different transverse displacements of wheelset, and the contact stress is distributed in the concentric ellipse form. Using the non-Hertz contact theory to calculate the contact area is more complex, and it varies greatly with the transverse displacement of the wheelset. The difference between the maximum contact stresses calculated by the two theories is not significant, and the greater the transverse displacement of the wheelset has, 


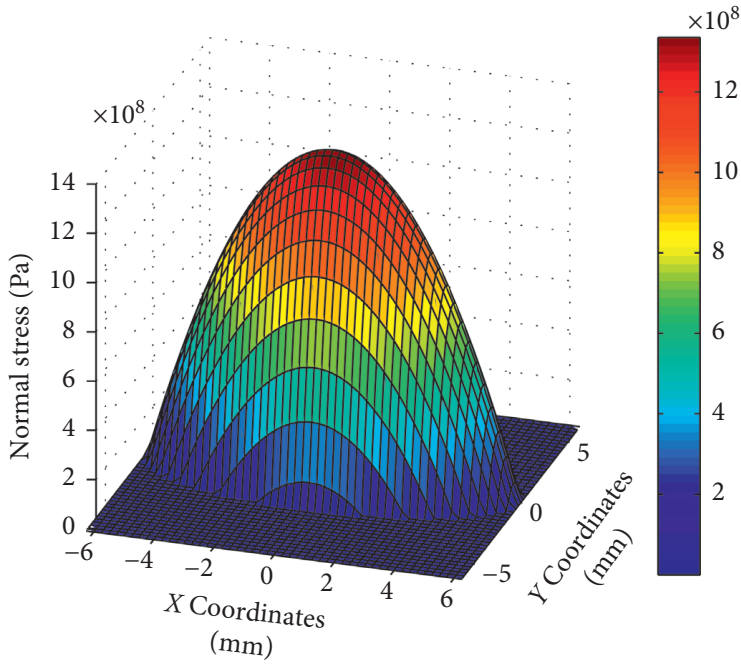

(a)

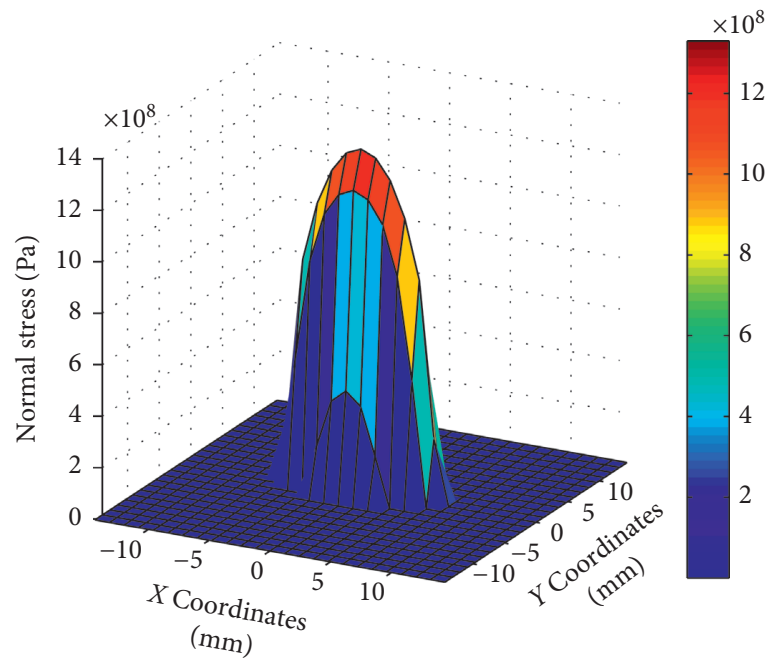

(b)

FIGURE 1: Contact pressure distribution (wheelset transverse displacement is $0 \mathrm{~mm}$ ) based on: (a) Hertz; (b) non-Hertz.

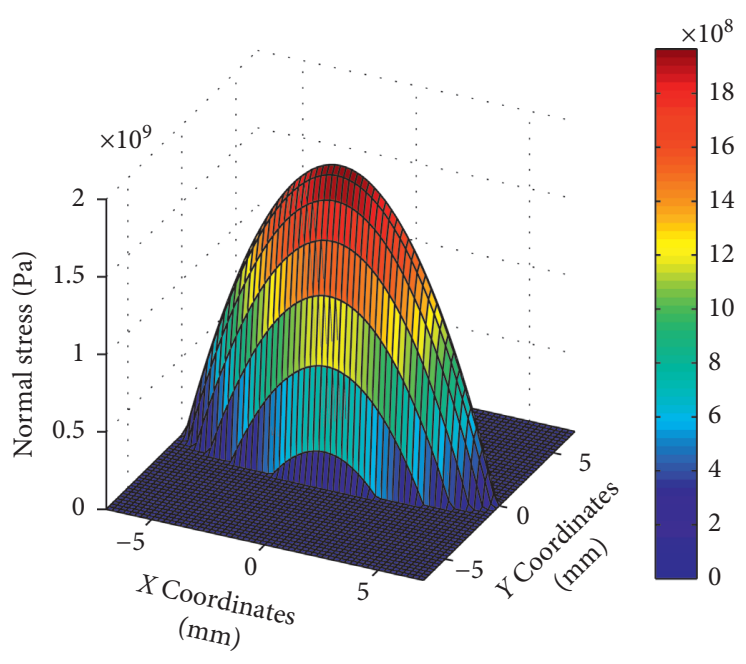

(a)

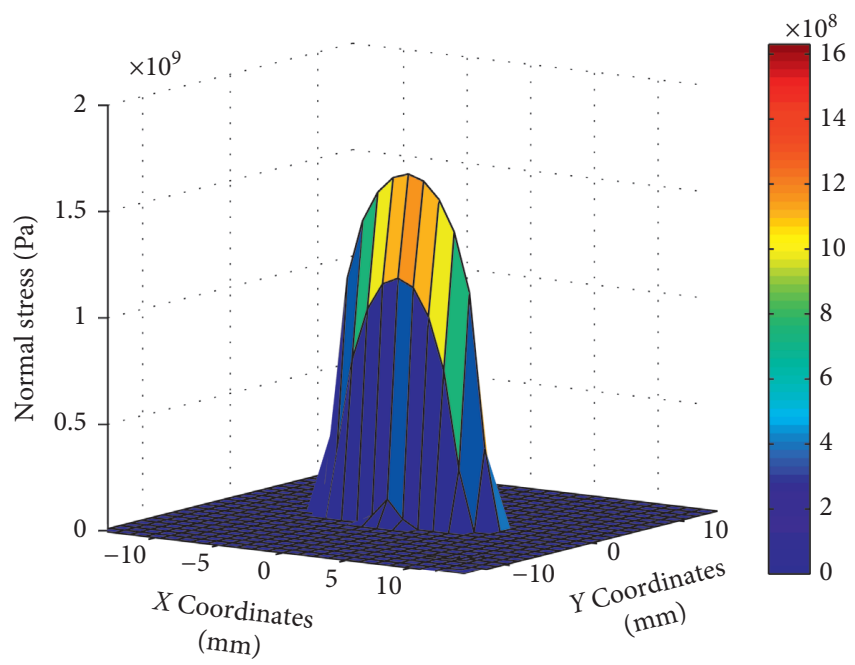

(b)

Figure 2: Contact pressure distribution (wheelset transverse displacement is $-3 \mathrm{~mm}$ ) based on: (a) Hertz; (b) non-Hertz.

the greater the error between them is. The main reason is that the contact area size required by Hertz contact theory is much smaller than the radius of the two contact objects, and the difference of the maximum contact stress is about $10 \%$. However, the calculation efficiency of Hertz contact theory is more than 10 times faster than that of non-Hertz contact theory. At the same time, Hertz contact theory can directly establish a relationship with rail radius, which facilitates the correction of rail profile. Considering comprehensively, Hertz contact theory is selected to calculate the normal contact stress between wheel and rail.

2.2. Objective Function. We aim to reduce the wheel-rail contact stress without deteriorating other dynamic performances. The optimization objective function is defined as the minimum total wheel-rail contact stress:

$$
\min P=\alpha_{1} \times P_{1}+\alpha_{2} \times P_{2}+\cdots \alpha_{n} \times P_{n}+\sum_{i=1}^{n} \alpha_{i} \times P_{i},
$$

where $P_{i}$ is the maximum wheel-rail contact stress and $\alpha_{i}$ is the weight coefficient. To get the available weighting coefficient, the lateral displacements of the wheelset are calculated using the vehicle-turnout coupling dynamics model $[25,26]$. The studied turnout is straight-through, and the lateral displacement is almost in the range from -4 to $4 \mathrm{~mm}$, so in this region, the greatest weighting factors should be considered. $n$ is the number of points with maximum contact stress within the optimization range. 


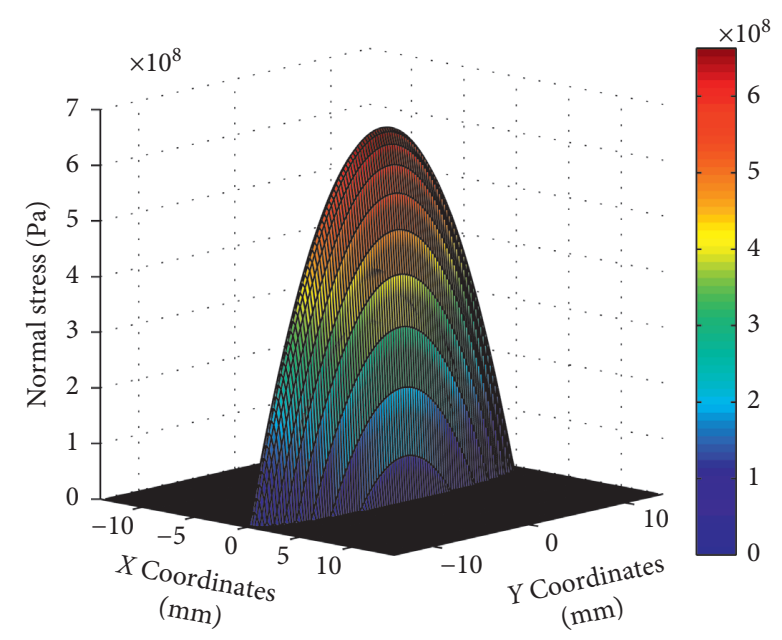

(a)

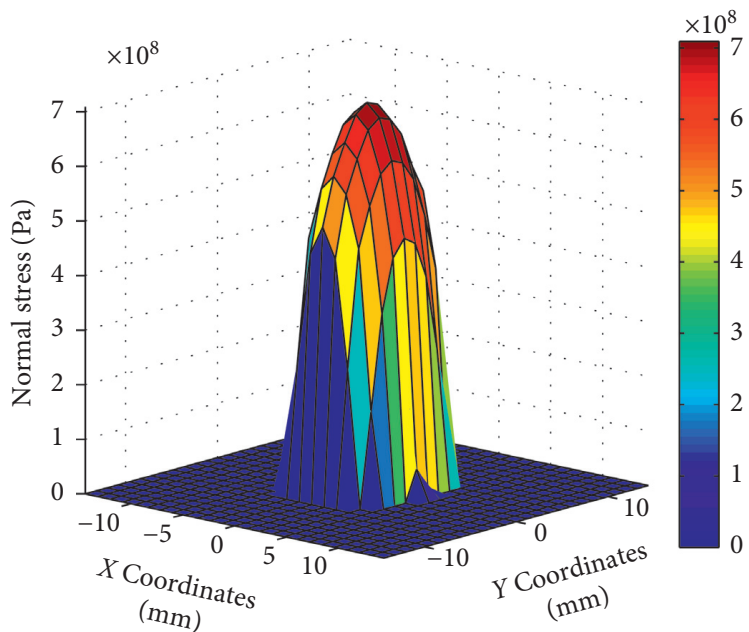

(b)

FIGURE 3: Contact pressure distribution (wheelset transverse displacement is $-6 \mathrm{~mm}$ ) based on: (a) Hertz; (b) non-Hertz.

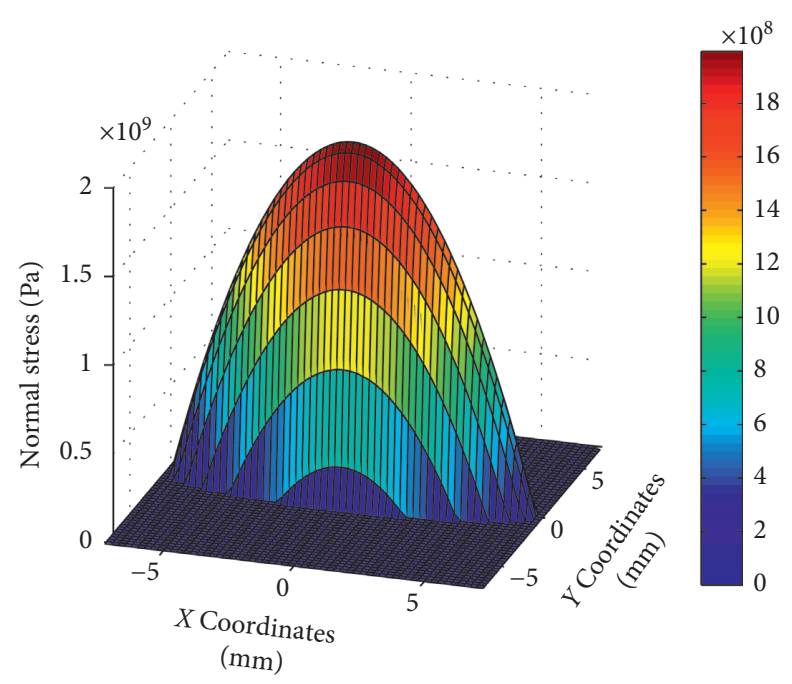

(a)

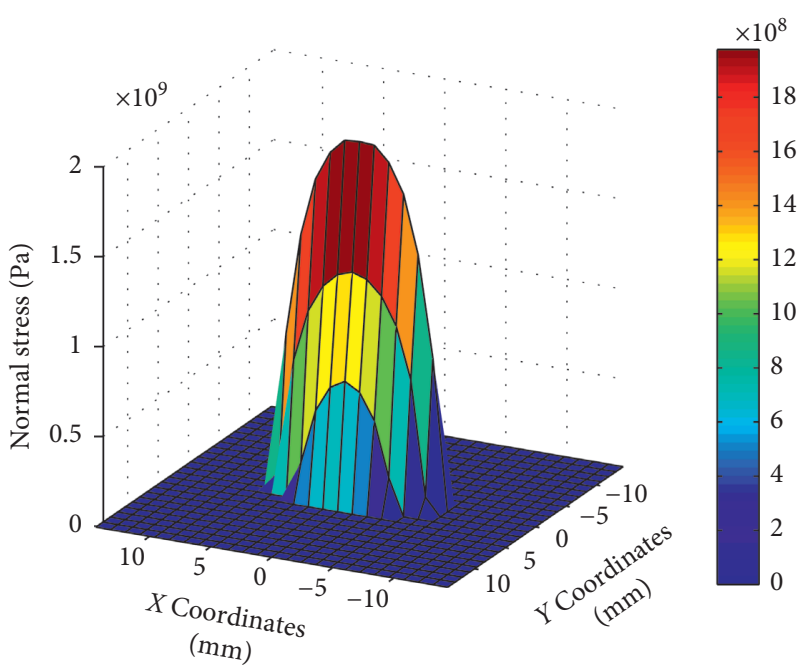

(b)

FIGURE 4: Contact pressure distribution (wheelset transverse displacement is $-9 \mathrm{~mm}$ ) based on: (a) Hertz; (b) non-Hertz.

2.3. Design Constraints. The geometric shape of the rail profile is a strict convex curve (excluding the sag region formed by the stock rail and nonworking side of switch points, where there is no wheel-rail contact and no optimization needs to be performed). It satisfies the following condition:

$$
\operatorname{sign}\left(\frac{d^{2} z_{r l}}{d y_{r l}^{2}}\right)=\operatorname{sign}\left(\frac{d^{2} z_{r r}}{d y_{r r}^{2}}\right) \equiv 1
$$

To avoid reciprocating points on the optimized profile, the horizontal coordinates of the optimized region should be kept as monotonic as possible. This yields the following:

$$
y_{i+1}>y_{i}
$$

As for grinding profile design, the designed rail profiles should not exceed the original one, then

$$
\begin{aligned}
& y_{\text {ref }}>y_{\text {opt }}, \\
& z_{\text {ref }}>z_{\text {opt }},
\end{aligned}
$$

where $\left(y_{r l}, z_{r l}\right)$ and $\left(y_{r r}, z_{r r}\right)$ are the coordinates of the left and right rails, respectively.

2.4. Optimization Algorithm. As shown in Figure 5, the rail profile of turnout from $B$ to $C$ is chosen as an optimization region. The starting point $B$ and the end point $C$ are the points on the profile corresponding to the expected contact stress $P_{\text {exp. }}$. The moving points $\left(y_{i}, z_{i}\right)$ on the profile can be set 


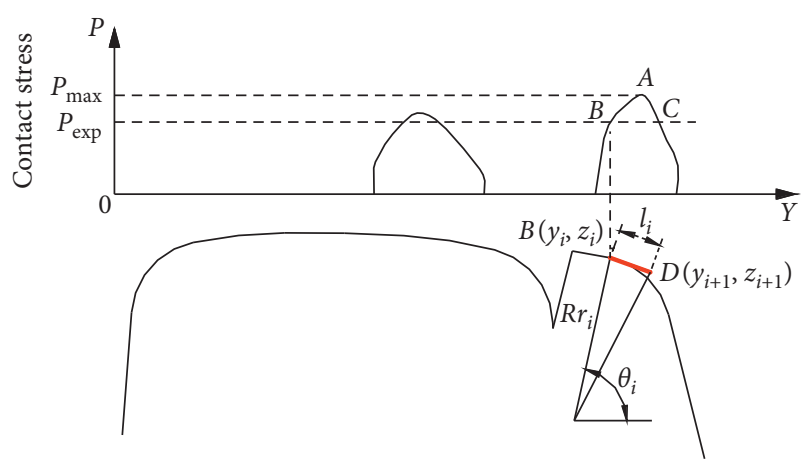

FIgURE 5: Schematic of rail profile design variables.

by dividing the tread from $\mathrm{B}$ to $\mathrm{C}$ into $n+1$ segments, where $y_{i}$ and $z_{i}$ are the lateral and vertical coordinates of the moving points, respectively. The coordinate of the moving point is the optimization variable. The latter moving point is recursively derived from the previous moving point.

The reverse design is performed to obtain the rail profile based on the rail radius. Given the coordinates of the starting point, the coordinates of the next point are directly calculated from the arc radius:

$$
\begin{aligned}
& y_{i+1}=y_{i}+R r_{i} \times\left(-\sin \left(\theta_{i}\right)+\sin \left(\frac{\theta_{i}+l_{i}}{R r_{i}}\right)\right), \\
& z_{i+1}=z_{i}+R r_{i} \times\left(\cos \left(\theta_{i}\right)-\cos \left(\frac{\theta_{i}+l_{i}}{R r_{i}}\right)\right),
\end{aligned}
$$

where $\left(y_{i}, z_{i}\right)$ and $\left(y_{i+1}, z_{i+1}\right)$ are the $i^{\text {th }}$ and $(i+1)^{\text {th }}$ points on the rail, respectively; $R r_{i}$ is the radius of the $i^{\text {th }}$ point; $\theta_{i}$ is the angle of the $i^{\text {th }}$ point on the arc with a radius of $R r_{i}$; and $l_{i}$ is the arc length between the $i^{\text {th }}$ and $(i+1)^{\text {th }}$ points.

2.5. Convergence Conditions. To minimize the contact stress of the optimized profile, the objective function needs to be tested. This requires

$$
\Delta P=\left|P_{k}-P_{k-1}\right|<\varepsilon,
$$

where $P_{k}$ and $P_{k-1}$ are the total wheel-rail contact stresses for the current iteration and the previous iteration, respectively, while $\varepsilon$ is the convergence tolerance. The tolerance $\varepsilon$ should not be too large; otherwise, it will lead to rapid convergence of the program, limiting the effectiveness of the optimization for rail profile. It should not be too small, either. Too small value will influence the convergence of the program. The recommendation value is about $3 \%$.

In the optimization design, if $P_{k}>P_{k-1}$, the profile obtained from this iteration is considered invalid, and then the next iteration begins.

\subsection{Major Steps of the Optimization Design}

(1) First, the wheel tread and the referenced ungrinded rail profile (rail profile to be optimized) at the turnout and parameters of wheel-rail contact are given. Geometric matching between wheel and rail is computed. Meanwhile, the maximum wheel-rail contact stress under different lateral displacements is calculated for the wheelset by using the Hertz contact theory. The maximum wheel-rail contact stress is the object of optimization.

(2) The position of the contact point between the rail profile and wheel profile at the turnout is determined based on the maximum contact stress $P_{\max }$. The radius of the contact point between the rail and wheel is also calculated. The expectation $P_{\exp }$ of the contact stress is set based on the maximum contact stress $P_{\max }$ in the following equation:

$$
P_{\exp }=\sigma P_{\max },
$$

where is the adjustment coefficient of the contact stress expectation. The optimization interval for the rail profile is configured based on the contact stress expectation, as shown in Figure 6.

(3) Assume that the position of the contact point on the wheel is fixed. The radius at the contact point on the rail is adjusted, and the maximum contact stress $P=\operatorname{Hertz}(R r)$ under different radii can be calculated by using the Hertz contact theory. From stress expectation $P_{\exp }$ and $P=\operatorname{Hertz}(R r)$ in equation (11), the expectation of a radius at the contact point on the rail is calculated, as shown in Figure 7.

(4) According to Step (1), it is assumed that the rail radius varies linearly from the starting point $B$ of the optimization interval to point $\mathrm{A}$ with the maximum contact stress. Then the radius for the optimization interval from $\mathrm{B}$ to $\mathrm{A}$ is

$$
R r_{i}=R r_{B}+\frac{R r_{A}-R r_{B}}{n_{B A}} \times i .
$$

The radius for the optimization interval $\mathrm{AC}$ is

$$
R r_{i}=R r_{A}+\frac{R r_{A}-R r_{C}}{n_{A C}} \times i \text {. }
$$

where $n_{B A}$ and $n_{A C}$ are the numbers of total points in the optimization interval $\mathrm{BA}$ and $\mathrm{AC}$, respectively, while $R r_{B}, R r_{A}$, and $R r_{C}$ are the radii of rail at points $\mathrm{B}, \mathrm{A}$, and $\mathrm{C}$, respectively.

Based on the radius, the optimized profile for the optimization interval $\mathrm{BC}$ is reversely designed.

(5) By splicing the optimum interval $B C$ with the reference profile, the complete profile of the optimum design can be obtained. Geometric matching between the wheel and rail is computed for the rail profile design at the turnout. The current maximum contact stress is calculated and compared to the initial maximum value. If the current maximum contact stress is smaller than the initial one but larger than the convergence tolerance, the expectation of the maximum contact stress and optimization interval are adjusted, and then (2) is executed. If the current maximum contact stress is larger than the 


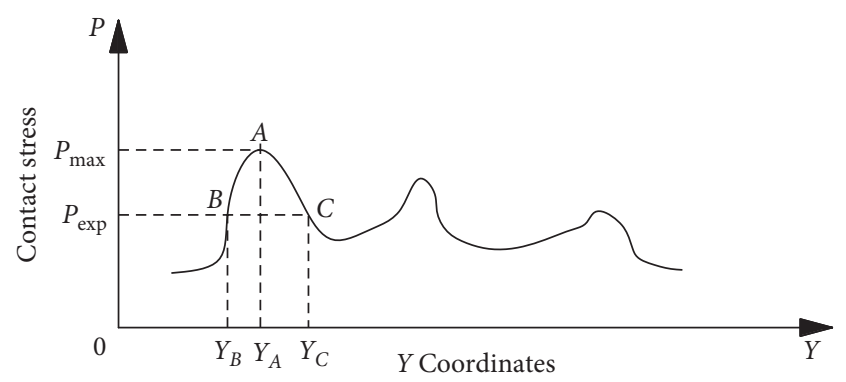

FIGURE 6: Schematic for the maximum wheel-rail contact stress distribution.

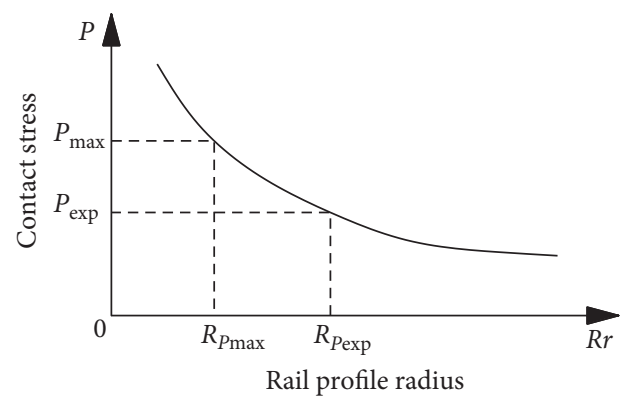

Figure 7: Schematic of relationship between contact stress and radius in rail profile design.

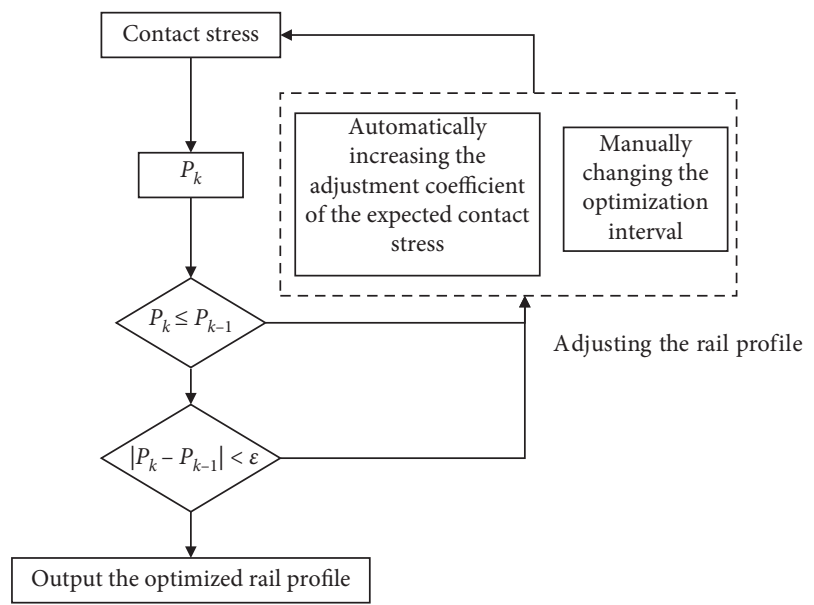

FIGURE 8: Flowchart of optimal convergence condition of the rail profile.

initial one, the optimization is considered ineffective and then the expectation of the maximum contact stress and optimization interval also need to be adjusted, and then (2) is executed. If the current maximum contact stress is smaller than the initial one and does not exceed the convergence tolerance, then the optimization design is performed for the next peak point. The iteration is terminated when all peak points have been optimized. The optimized rail profile at the turnout is obtained as output.

When the adjustment coefficient of the expected contact stress and optimization interval are given, the program will be performed to obtain the optimized design. When the first optimization design is completed, the program will automatically recalculate the contact stress between wheels and rails. Automatic judgment will be made according to Figure 8. If it is necessary to adjust the rail profile, the program will first automatically increase the adjustment coefficient and then perform optimization calculation. The program will not stop until the adjustment coefficient of the expected contact stress reaches 1 . At that time, it is necessary to manually adjust the optimization interval, and then the program proceeds to the optimization design calculation again until the final optimized profile was generated as output.

The flowchart for the optimization design of the rail profile is presented in Figure 9. An iteration program in MATLAB has been developed and realized.

\section{Results and Discussion}

The proposed method is verified through a specific example, which is the optimization design of a key cross section of No. 12 ordinary single turnout (CN60-350-1:12; curve radius of $350 \mathrm{~m}$; frog angle of $1: 12$ ). Due to the limited space of this paper, only one key cross section with a switch point width of $20 \mathrm{~mm}$ and a wheel profile (type: China LM worn type) was included in the case study. The inner-side distance of the wheelset is $1353 \mathrm{~mm}$, track gauge is $1435 \mathrm{~mm}$, and rail bottom slope is $1 / 40$. The nominal rolling circle radius of the wheel is $475.5 \mathrm{~mm}$, and the axle load is 17 tons.

As shown in Figure 10, during the dynamic lateral displacement of wheelset (lateral displacement of wheelset from -12 to $+12 \mathrm{~mm}$ ), the contact stress between the wheel and rail gradually decreases from the working side to the centerline of the rail. The wheel-rail maximum contact stress appears at the inner side of the railhead (closer to the working side). Here the contact stress has far exceeded the rail limit of stability. The main reason is that the radius at this contact point on the wheel is an anticircular arc with $R=100 \mathrm{~mm}$, while that on the rail is a circular arc with $R=13 \mathrm{~mm}$. This implies that the inner side of the railhead is the first region to suffer the rolling contact fatigue. This coincides with the occurrence of an oblique crack at the inner side of the railhead as shown in Figure 11 and also with the calculation of region with the maximum contact stress in Figure 10. The calculation results hold high similarity with the on-site inspection data. To slow down the development of fatigue cracks, it is necessary to optimize the rail profile of this region and reduce the respective contact stress.

The rail profiles before and after optimization are shown in Figure 12. The respective differences are quite obvious, and the optimized profile can be obtained by grinding with the grindstone. The changes in the radius of the rail profile before and after optimization are shown in Figure 13: several broken straight lines are replaced by continuous curves, which are good for the contact performance between the wheel and rail. When the wheelset has a dynamic lateral displacement, contact points will not jump greatly on the wheel tread or rail top surface. Consequently, the wheel-rail 


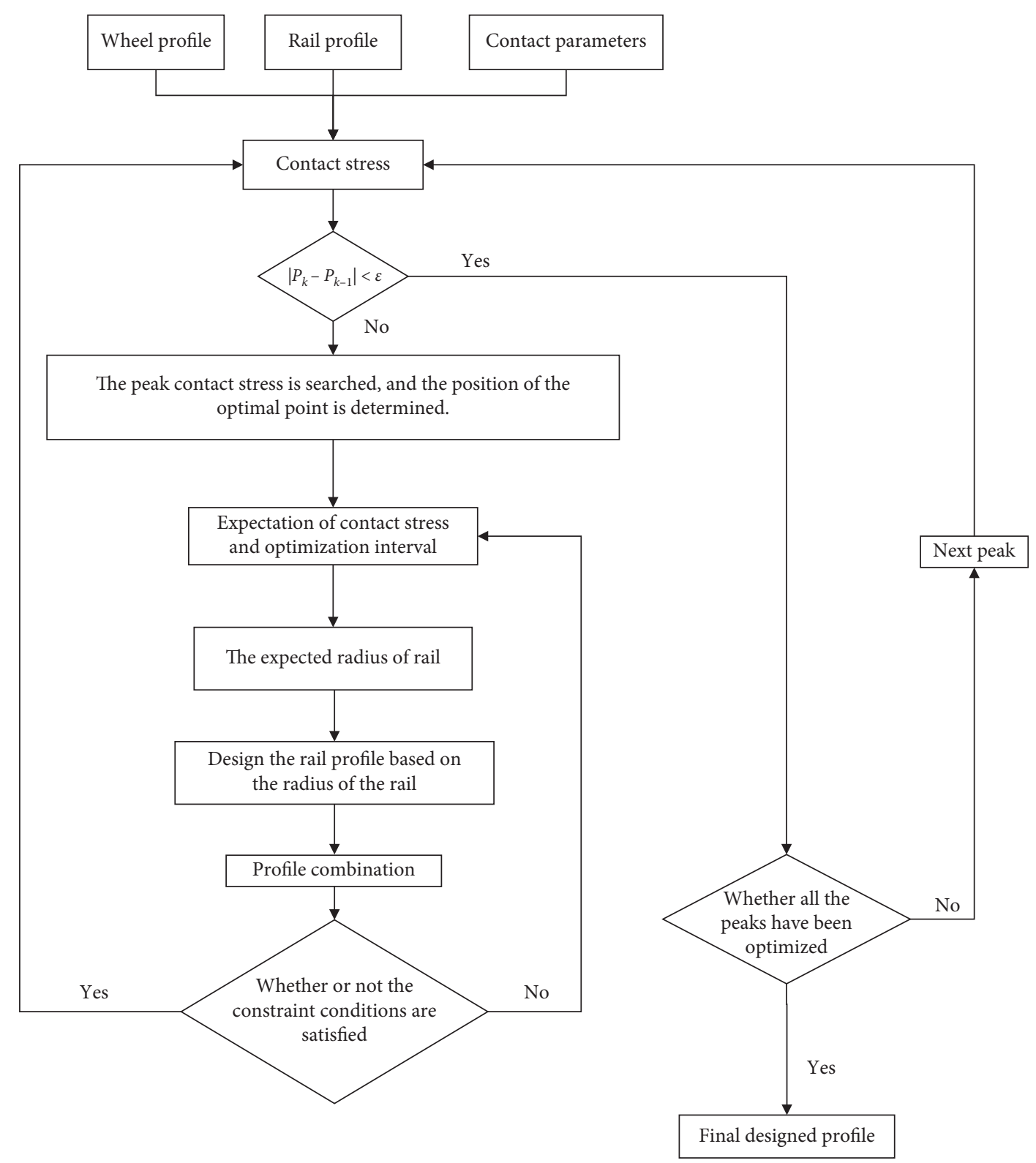

FIgURE 9: Flowchart of the rail profile optimization.

contact stress will not fluctuate significantly when the contact points move from one arc to another.

A comparison of maximum wheel-rail contact stress before and after optimization is presented in Figure 14, which implies that the maximum contact stress after the optimization has been reduced significantly. Thus, in the left rail at the turnout, it drops from 6140 to $5684 \mathrm{MPa}$ or by $7.5 \%$. When the lateral displacement is from -8 to $3 \mathrm{~mm}$, the contact stress decreases by $52 \%$ in maximum. The maximum contact stress on the right rail decreases from 5867 to $5342 \mathrm{MPa}$ or by $8.9 \%$; when the lateral displacement is from $-6.5 \mathrm{~mm}$ to $2.5 \mathrm{~mm}$, the contact stress decreases by $42.3 \%$ in maximum. These results prove that the optimized rail profile can effectively reduce the wheel-rail contact stress.

The normal pressure distribution in the contact patches on the left side (switch rail) of wheel-rail was calculated and is plotted in Figure 15. The maximum normal pressure of the optimized profile appears to be lower than that of the nominal profile when the transverse displacement of the wheelset is zero due to a larger area of the contact patch on tangent track. The optimized rail profile reduces the possibility of fatigue damage of the rail contact surface and might prolong the rail service life.

Distributions of wheel-rail contact points for the LM worn-type tread before and after optimization with the wheel and rail match are shown in Figures 16 and 17, respectively. Before optimization, when the lateral displacement of the wheelset is from -6 to $-7 \mathrm{~mm}$, the contact points move from the stock rail to the switch points; after optimization, that happens when the lateral displacement of wheelset varies from -8 to $-9 \mathrm{~mm}$. In this case, the wheels will not come into contact with the switch points too early, 


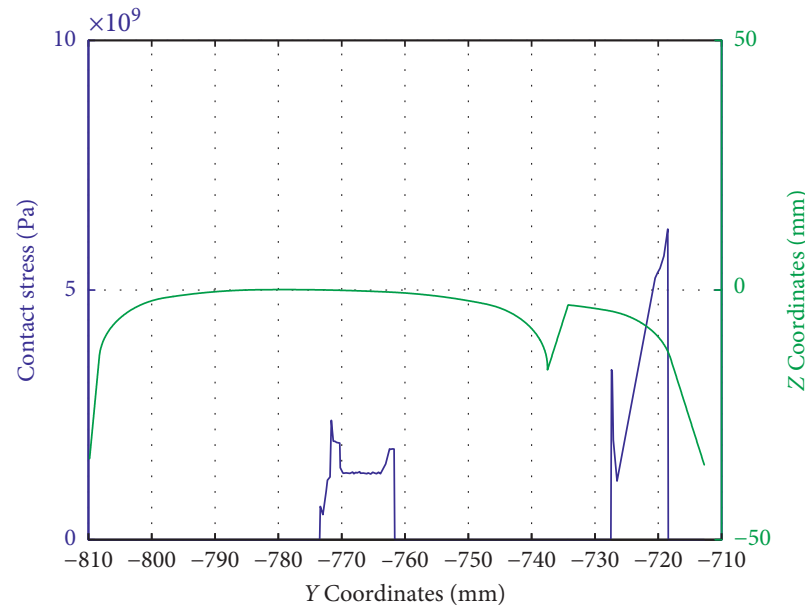

(a)

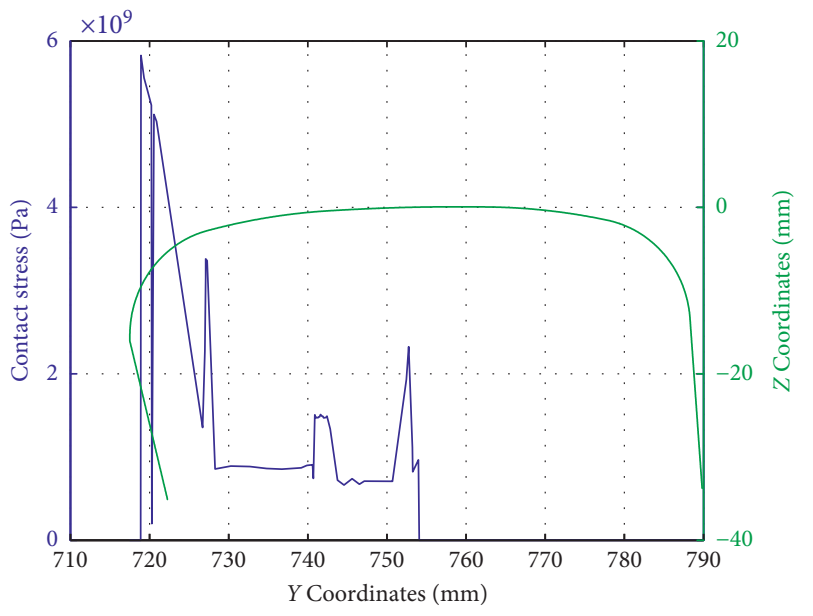

(b)

Figure 10: The maximum contact stress between the wheel and switch rail (a) and between the wheel and stock rail (b). The green lines correspond to the rail profile, while blue ones depict the contact stress.

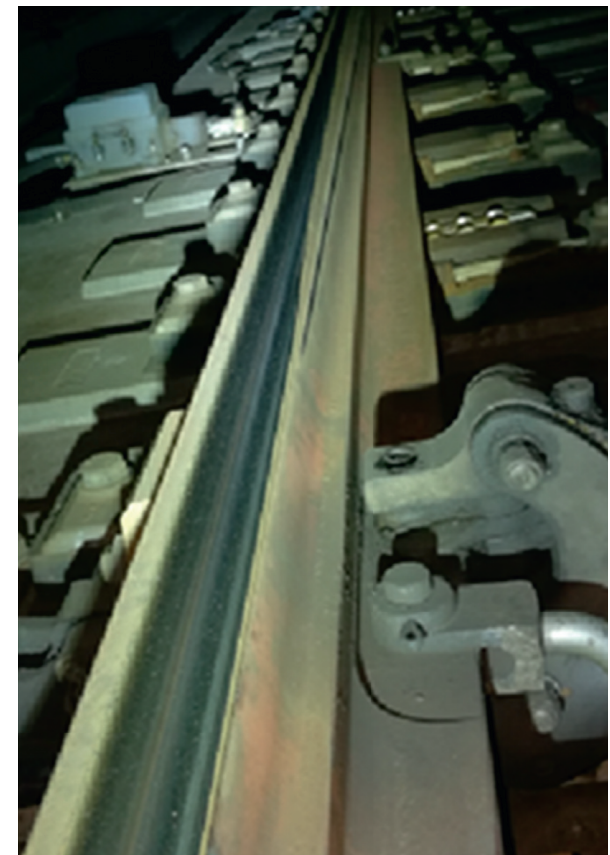

FIGURe 11: Photo of the rail with an oblique crack at the inner side of the railhead at the turnout.

which will reduce switch point wear. When the lateral displacement of the right stock rail is close to zero, the distribution of contact points on the rail is more uniform after optimization than before; besides, the contact zone on the rail is wider, which is conducive to reduce the contact frequency at the same point, relieving the rail wear and prolonging the service life of the rail.

For the brevity sake, we have only given an optimized example of the switch rail with a width of $20 \mathrm{~mm}$. According to the abovementioned optimization method, other control cross sections such as the width of $0 \mathrm{~mm}, 35 \mathrm{~mm}, 50 \mathrm{~mm}$, and $70 \mathrm{~mm}$ can be optimized in the same way. Each rail profiles were generated by longitudinal interpolation. Two adjacent control cross sections around the targeted location are shown in Figure 18 [10, 26].

Although turnouts can be designed separately by dividing them into several control sections, each section is not completely independent, and the longitudinal relationship of each section needs to be considered. In order to reduce the dynamic impact of vehicles passing through the turnout, the longitudinal wheel-rail contact points should be as smooth as possible. Along the longitudinal direction of the switch, the transverse width of the contact area may be very narrow, and the influence of the jump of the contact point on the lateral operation of the wheel will be reduced, which is beneficial to enhancing the stability of the vehicle and reducing the lateral force of the wheel-rail. Thus another object function can be defined as follows:

$$
\begin{aligned}
\text { obj: } \min \left(\max \left|y_{w l}\left(y_{w}=m\right)-y_{w l}\left(y_{w}=n\right)\right|\right. \\
\left.+\max \left|y_{w r}\left(y_{w}=m\right)-y_{w r}\left(y_{w}=n\right)\right|\right),
\end{aligned}
$$

where $m$ is the minimum traverse of wheelset and $n$ is the maximum traverse of wheelset.

To ensure that the optimized profile will not appear as a wavy shape in the vertical direction, the maximum grinding depth of the each optimized profile is set as a constant. In the actual grinding operation, the designed grinding profile is compared with the measured profile, and the noncritical cross sections are interpolated to generate a three-dimensional grinding volume [27].

\section{Dynamic Interaction of Vehicle and Turnout}

In this verification study, the standard MATLAB and SIMULINK software packages were used to construct a passenger rail vehicle (Chinese PW220-K) model and simulate the dynamic responses of the vehicle passing through a straight turnout before and after the optimization. 


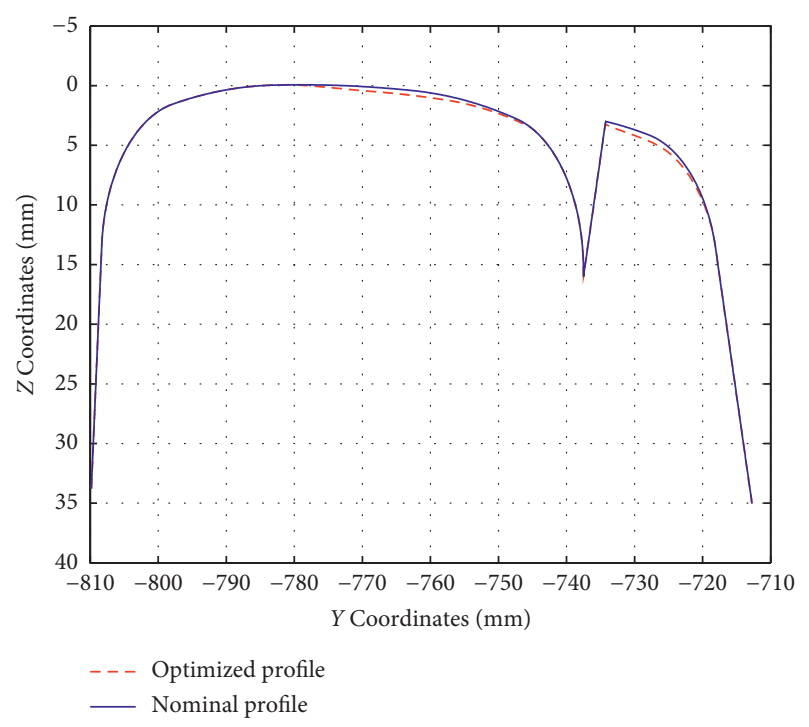

(a)

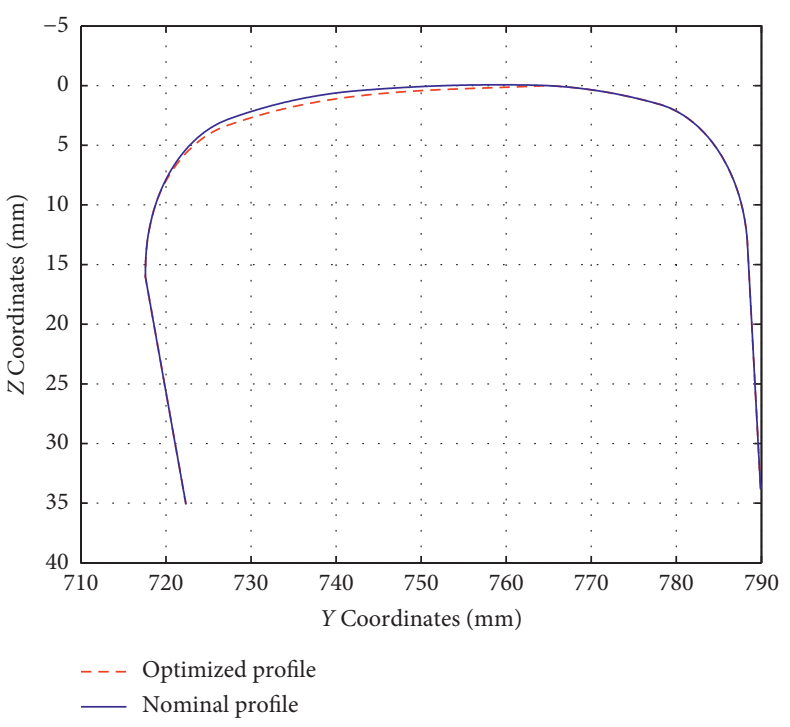

(b)

FIgURE 12: Comparison of rail profiles before and after optimization: (a) switch rail and (b) stock rail.

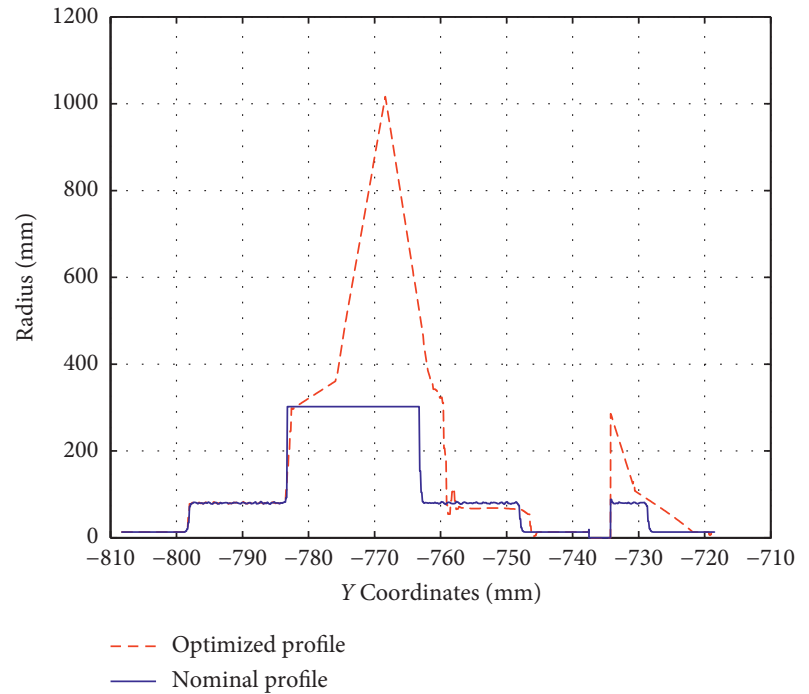

(a)

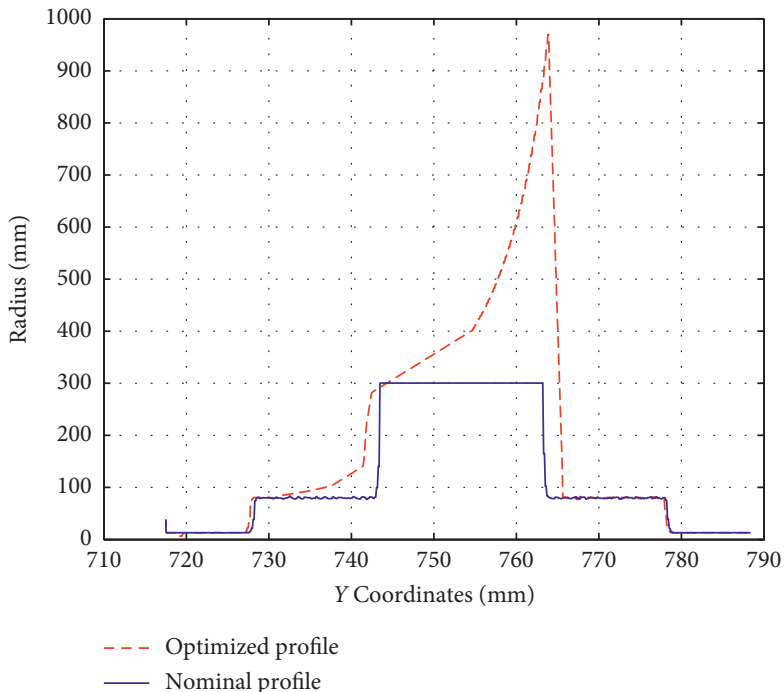

(b)

FiguRE 13: Distribution of radius of the rail profile before and after optimization: (a) switch rail and (b) stock rail.

Using the LM-type wheel tread, a rail vehicle passage of a CN60-350-1:12 turnout was simulated.

The matrix assembly method is used to construct the vehicle dynamic module. It can be described as [28]

$$
[M] \ddot{x}+[C] \dot{x}+[K] x=F,
$$

where $[M],[C]$, and $[K]$ are the system mass, damping, and stiffness matrix, respectively. $F$ is the generalized force vector. $x$ is the response vector.

In the wheel-rail contact model, the SHEN-Hedrick theory is used to solve the tangential contact problem. First, it is calculated according to Kalker's linear creep theory, and then the SHEN-Hedrick method is used to correct the creep saturation. When the suspension force and the wheel-rail tangential force are already known, the normal contact force of the wheel-rail is obtained by solving the equation of motion of the wheelset. The force diagram of the wheelset under dynamic equilibrium is shown in Figure 19.

The variable names are explained as follows: $\phi_{w}$ is the roll angle, and $\psi_{w}$ is the yaw angle; $\delta_{L} / \delta_{R}$ are the left/right-side contact angle; the left and right contact points $\left(C_{L}, C_{R}\right)$ are defined as $\left(x_{c L}, y_{c L}, z_{c L}\right)$ and $\left(x_{c R}, y_{c R}, z_{c R}\right)$, respectively; $N_{L} / N_{R}$ are the normal force of the left/right contact points; $T_{L} / T_{R}$ are the tangential force of the left/right contact points; $M_{T x L} / M_{T x R}$ are the rotation moment of the left/right contact points; $F_{s z L} / F_{s z R}$ are the vertical component of left/ right suspension forces; $M_{s x L} / M_{s x R}$ are the longitudinal component of left/right suspension moment; $F_{a z} / M_{a x}$ are 


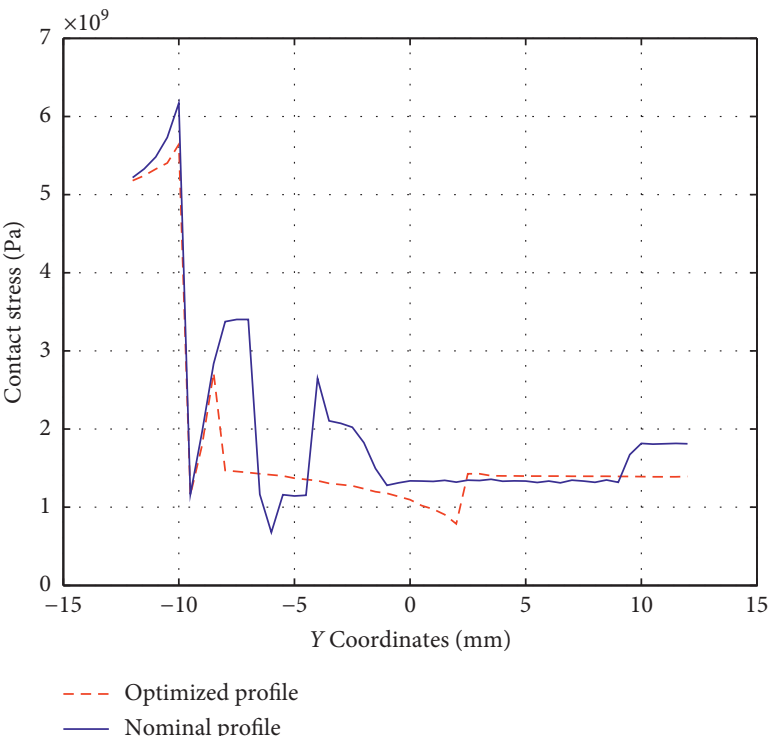

(a)

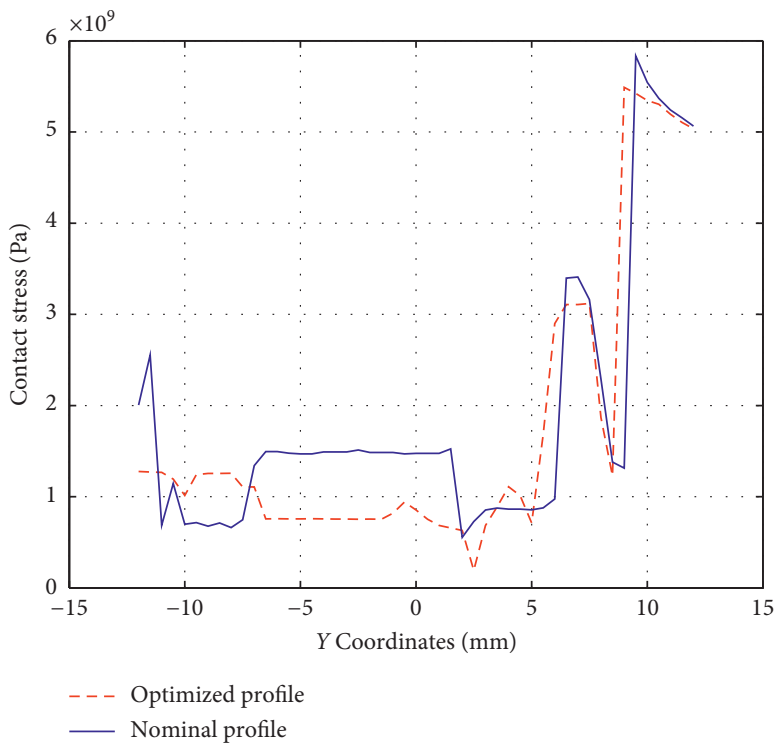

(b)

FIgURE 14: Maximum wheel-rail contact stress before and after optimization: (a) switch rail and (b) stock rail.

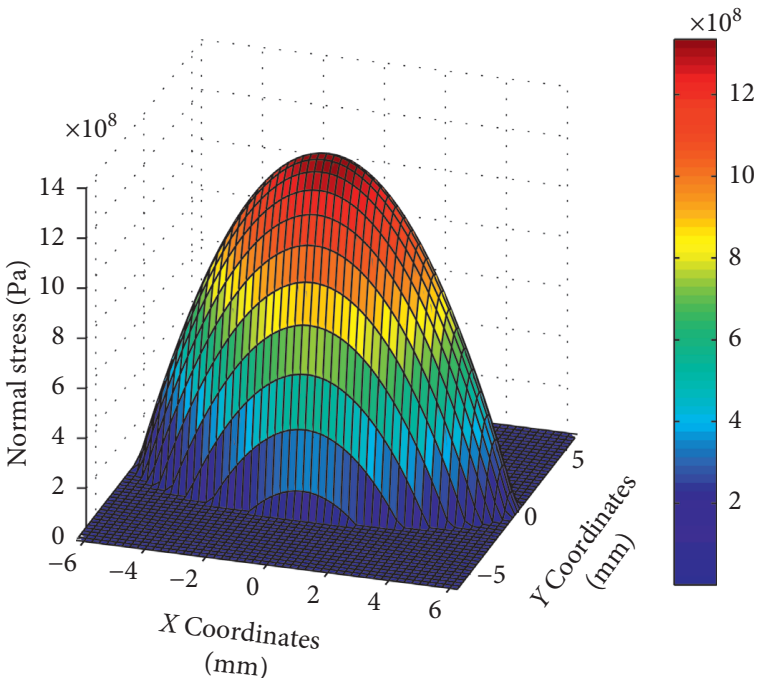

(a)

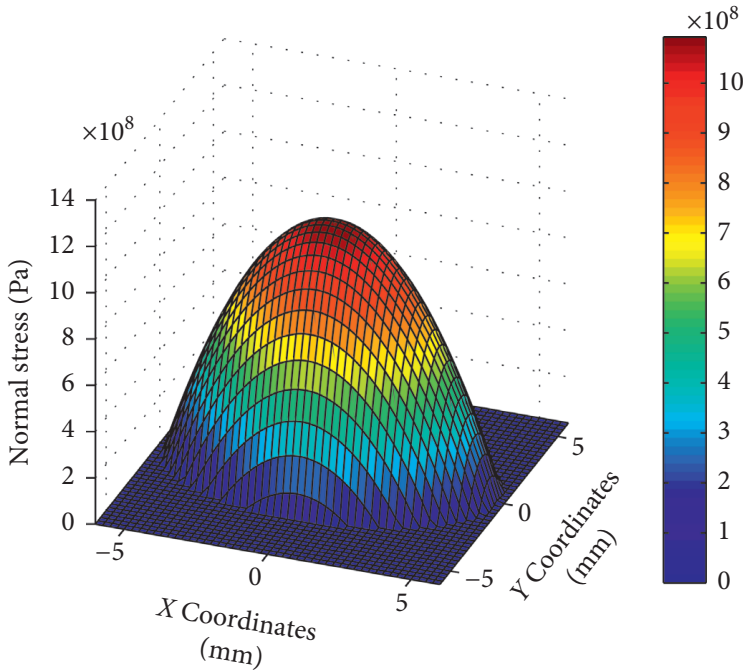

(b)

FIgURE 15: Distribution of the normal pressure: (a) before optimization and (b) after optimization.

the inertial force/moment of wheelset; and $F_{I G z} / M_{I G x}$ are the inertial force/moment caused by the change of the rail coordinate system.
After ignoring some high-order small quantities, the wheelset equilibrium equation becomes

$$
\left[\begin{array}{cc}
\cos \left(\delta_{R}+\phi_{w}\right) & \cos \left(\delta_{L}+\phi_{w}\right) \\
S & W
\end{array}\right]\left\{\begin{array}{c}
N_{R} \\
N_{L}
\end{array}\right\}=\left[\begin{array}{c}
F_{a z}-F_{I G}-F_{s z L}-F_{s z R}-T_{L}-T_{R} \\
M_{a z}-M_{I G}-M_{s x L}-M_{s x R}-M_{T x L}-M_{T x R}
\end{array}\right]
$$

where $\quad S=\cos \left(\delta_{R}+\phi_{w}\right)\left(\psi_{w} x_{c R}+y_{c R}-\phi_{w} z_{c R}\right)+$ $\sin \left(\delta_{R}+\phi_{w}\right)\left(\phi_{w} y_{c R}+z_{c R}\right)$ and $W=\cos \left(\delta_{L}+\phi_{w}\right)\left(\psi_{w} x_{c L}+\right.$ $\left.y_{c L}-\phi_{w} z_{c L}\right)+\sin \left(\delta_{L}+\phi_{w}\right)\left(\phi_{w} y_{c L}+z_{c L}\right)$.
The normal force of wheel and rail can be obtained by solving equation (18). The overall flowchart of wheel-rail creep calculation is shown in Figure 20. The simulation is 


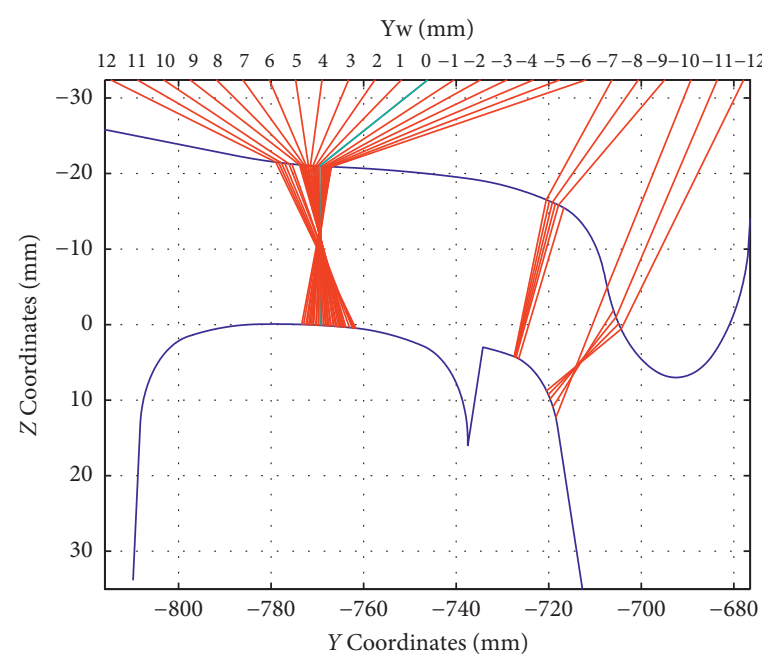

(a)

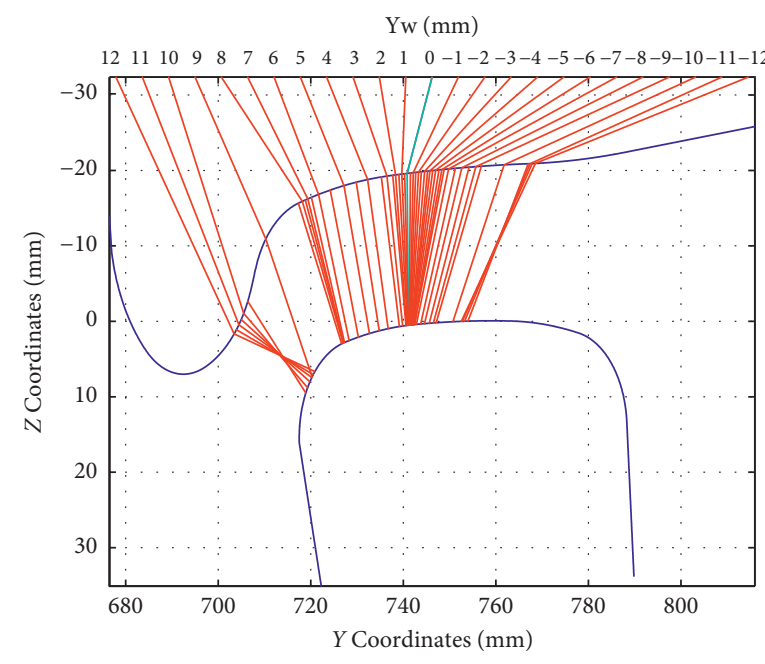

(b)

FIgURE 16: Distribution of wheel-rail contact points before optimization: (a) switch rail and (b) stock rail.

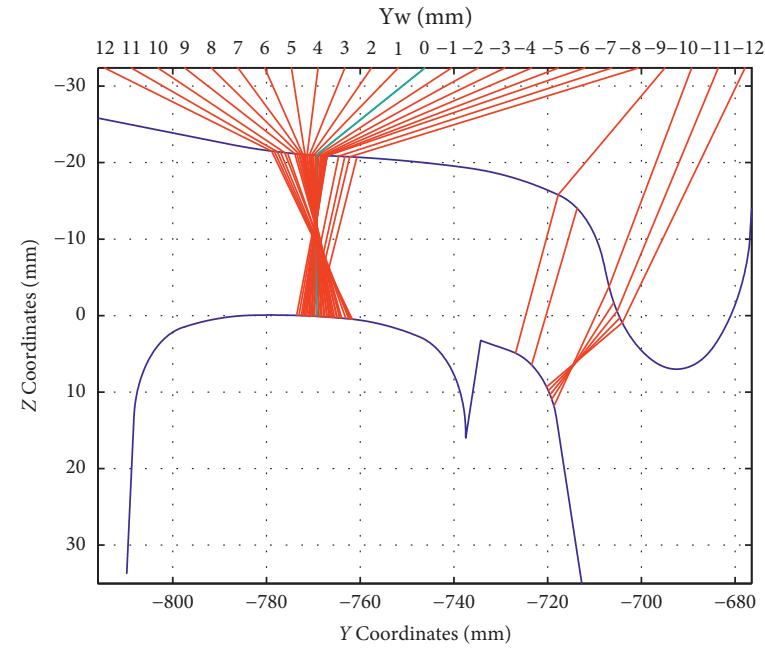

(a)

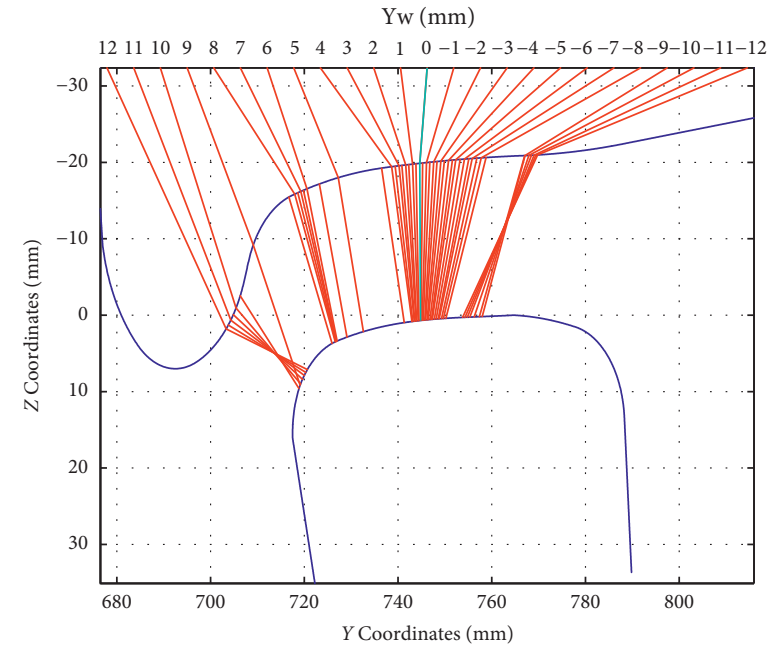

(b)

FIGURE 17: Distribution of wheel-rail contact points after optimization: (a) switch rail and (b) stock rail.

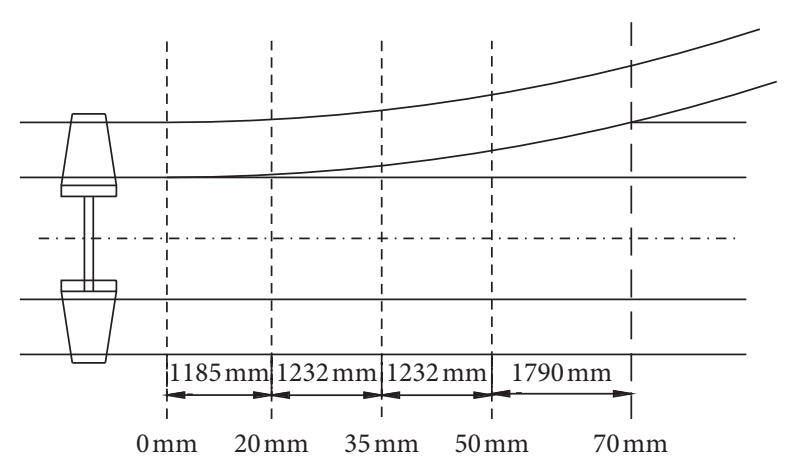

(a)

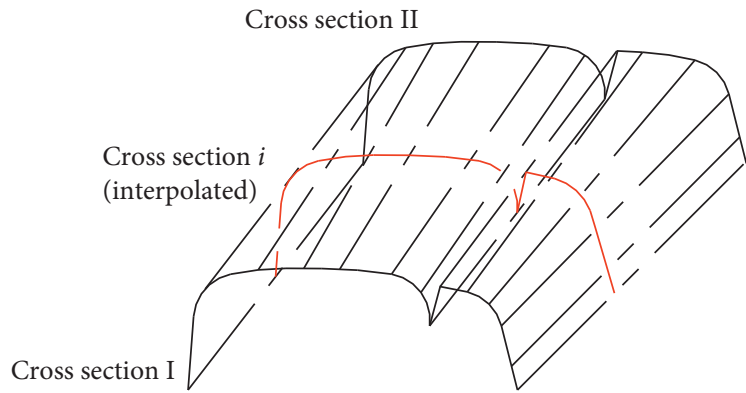

(b)

FIGURE 18: Rail profile in the switch: (a) control cross sections of the rail along the switch; (b) interpolation of the rail profile. 


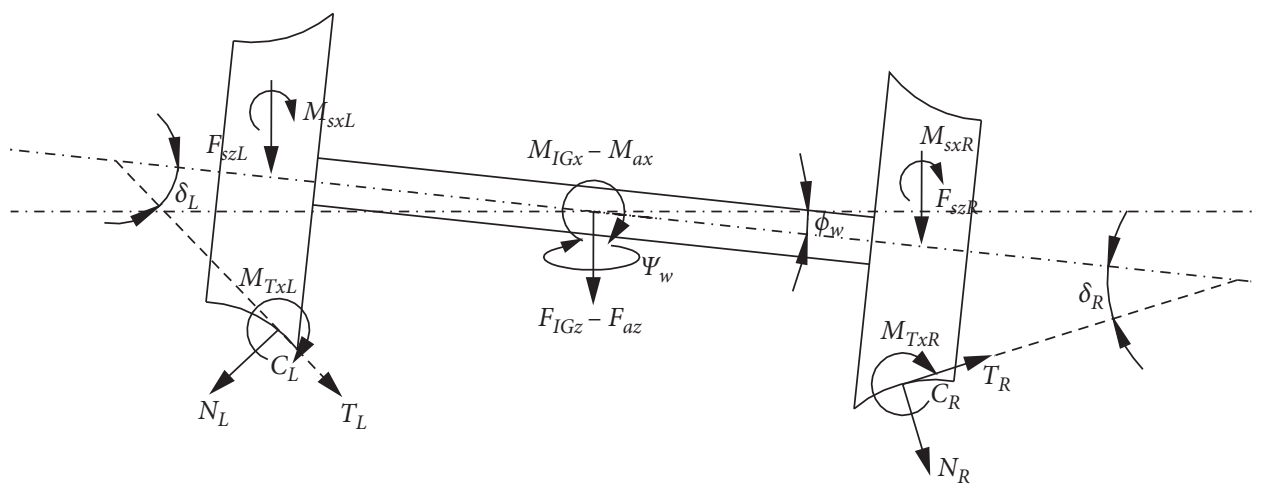

FIgUre 19: Force decomposition of wheelset.

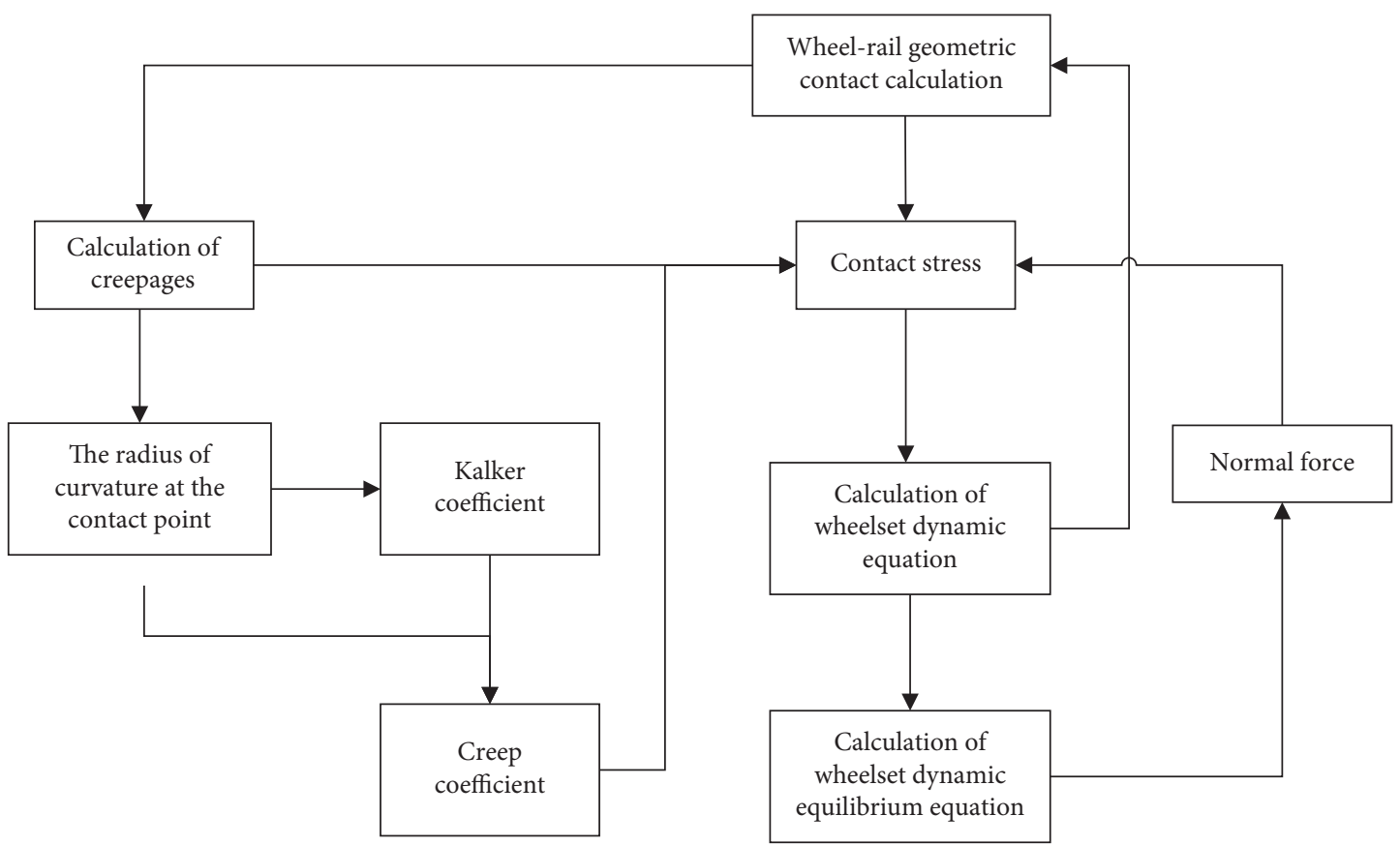

FIgURE 20: Flowchart of wheel-rail creep.

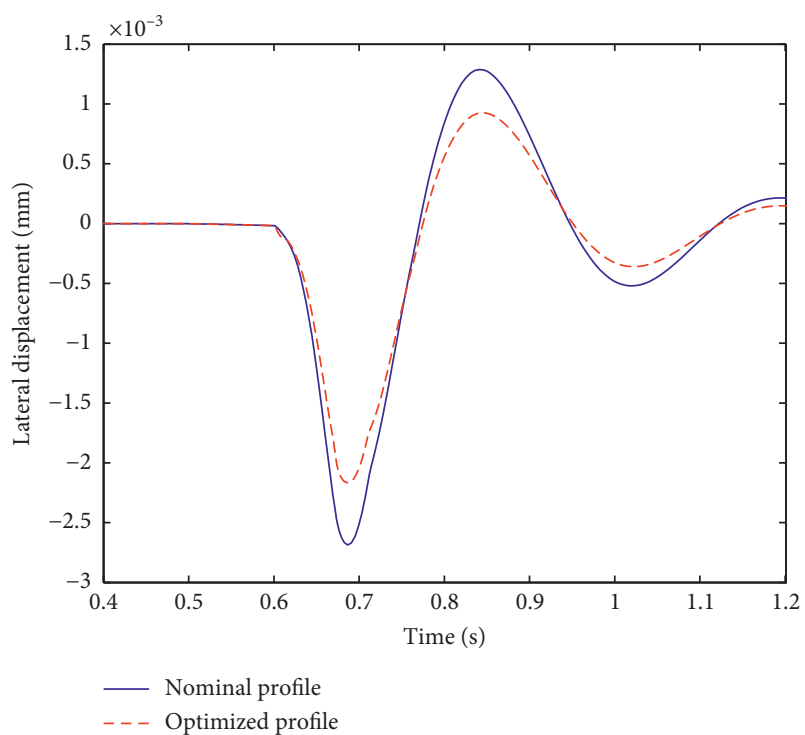

Figure 21: Lateral displacement of the first wheelset.

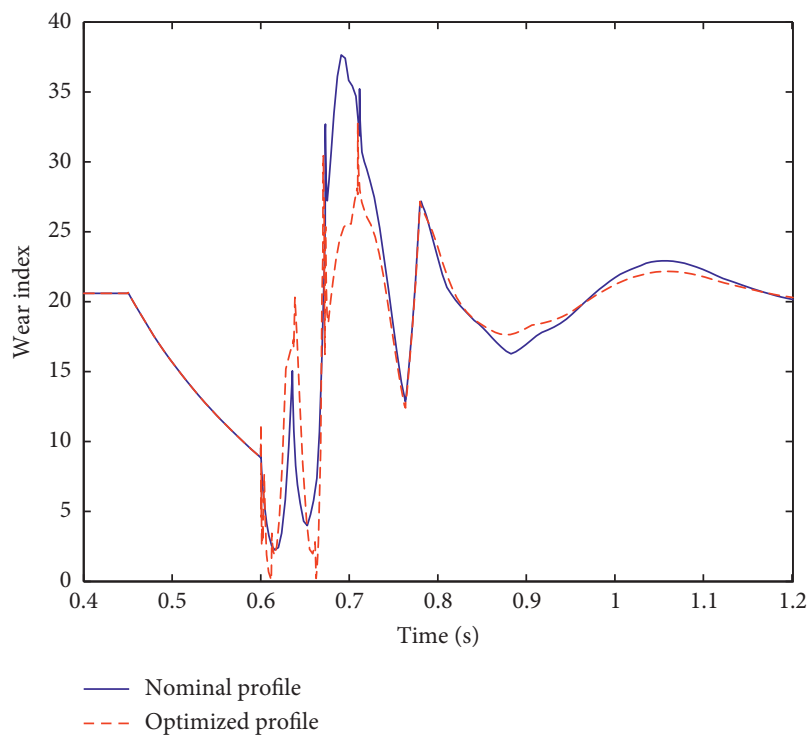

FIGURE 22: Wear indexes. 
carried out at the speed of $120 \mathrm{~km} / \mathrm{h}$ for the vehicle, and no track irregularity is imposed.

The lateral displacements of the first wheelset passing through this turnout with and without optimization are shown in Figure 21. When passing through the optimized turnout, the wheelset shows a much better performance of running back to the track center than before, and the lateral displacement of the wheelset is a little lower. The wear indexes [29] of the left wheel of the first wheelset before and after optimization are shown in Figure 22. After optimization, the maximum wear index is 31 vs. 37.6 , which implies a reduction of $17.5 \%$. This indicates that the optimized profile better matches the LM worn-type tread without deteriorating the dynamic performance of the vehicle passing the turnout.

\section{Conclusions}

A new direct numerical method is proposed to optimize the rail profile in the switch panel, minimizing the wheel-rail contact normal stress as the design objective. The relationship between the radius of rail profile and contact stress was initially established based on Hertz theory. Then the rail profile is designed by directly adjusting the radius of the curve. Although the rails in the turnout switch panel vary continuously along the longitudinal direction, several control sections can be selected for optimization design, and other rail profiles can be obtained through interpolation.

The design method not only ensures that the designed rail profile is smooth but also makes it easy to control the width of the design interval and the designed grinding depth. The optimization example shows that when the optimized rail profile at the turnout matches the LM worn-type wheel well, both the contact stress and geometry characteristic of wheel-rail contact are significantly improved. This is of high economic importance in terms of prolonging rail service life. The above findings may guide the selection of the target profile in the rail grinding operation. This optimization method is also applicable to the design of wheel and rail profile of the railway segment.

The profile optimization of the railway turnout is a longterm and complicated process; the rail profile in switch panel in diverging line and the profile of crossing nose are not considered in this work, and they should be studied in the future. As to high-speed railway turnout, the stability of the vehicle should be guaranteed first.

\section{Data Availability}

The profile data and software code used to support the findings of this study are currently under embargo, while the research findings are commercialized. Requests for data, 6 months after publication of this article, will be considered by the corresponding author.

\section{Conflicts of Interest}

The authors declare that they have no conflicts of interest.

\section{Acknowledgments}

The present work was supported by the Project of Science and Technology Research and Development Plan of China Railway Corporation (No. 2017G003-A).

\section{References}

[1] N. Burgelman, Z. Li, and R. Dollevoet, "A new rolling contact method applied to conformal contact and the train-turnout interaction," Wear, vol. 321, pp. 94-105, 2014.

[2] P. A. Cuervo, J. F. Santa, and A. Toro, "Correlations between wear mechanisms and rail grinding operations in a commercial railroad," Tribology International, vol. 82, pp. 265273, 2015.

[3] Y. Satoh and K. Iwafuchi, "Effect of rail grinding on rolling contact fatigue in railway rail used in conventional line in Japan," Wear, vol. 265, no. 9-10, pp. 1342-1348, 2008.

[4] I. Y. Shevtsov, V. L. Markine, and C. Esveld, "Optimal design of wheel profile for railway vehicles," Wear, vol. 258, no. 7-8, pp. 1022-1030, 2005.

[5] G. Shen and X. Zhong, "A design method for wheel profiles according to the rolling radius difference function," Proceedings of the Institution of Mechanical Engineers, Part F, Journal of Rail \& Rapid Transit, vol. 225, no. 5, pp. 457-462, 2011.

[6] D. B. Cui, L. Li, and X. S. Jin, "Optimal design of wheel profiles based on weighed wheel/rail gap," Wear, vol. 271, pp. 218226, 2001.

[7] R. Smallwood, J. C. Sinclair, and K. J. Sawley, "An optimization technique to minimize rail contact stresses," Wear, vol. 144, no. 1-2, pp. 373-384, 1991.

[8] X. Mao and G. Shen, "A design method for rail profiles based on the geometric characteristics of wheel-rail contact," Proceedings of Institution of Mechanical Engineers, Part F, Journal of Rail \& Rapid Transit, vol. 232, no. 5, pp. 1-11, 2017.

[9] E. E. Magel and J. Kalousek, "The application of contact mechanics to rail profile design and rail grinding," Wear, vol. 253, no. 1-2, pp. 308-316, 2002.

[10] C. Wan, V. L. Markine, and I. Y. Shevtsov, "Improvement of vehicle-turnout interaction by optimising the shape of crossing nose," Vehicle System Dynamics, vol. 52, no. 11, pp. 1517-1540, 2014.

[11] P. Wang, X. Ma, J. Wang, J. Xu, and R. Chen, "Optimization of rail profiles to improve vehicle running stability in switch panel of high-speed railway turnouts," Mathematical Problems in Engineering, vol. 2017, no. 2, pp. 1-13, 2017.

[12] B. A. Pålsson, "Design optimisation of switch rails in railway turnouts," Vehicle System Dynamics, vol. 51, no. 10, pp. 1619-1639, 2013.

[13] M. R. Bugarín, J. M. García, and D. D. Villegas, "Improvements in railway switches," Institution of Mechanical Engineers, Part F, Journal of Rail \& Rapid Transit, vol. 216, no. 4, pp. 275-286, 2002.

[14] J. R. Oswald, "Turnout geometry optimization with dynamic simulation of track and vehicle," in Proceedings of the Annual Conference, American Railway Engineering and Maintenance of Way Association, pp. 297-302, Dallas, TX, USA, September 2000.

[15] H. M. El-sayed, M. Lotfy, H. N. El-Din Zohny, and H. S. Riad, "A three dimensional finite element analysis of insulated rail joints deterioration," Engineering Failure Analysis, vol. 91, pp. 201-215, 2018. 
[16] N. Zong and M. Dhanasekar, "Sleeper embedded insulated rail joints for minimising the number of modes of failure," Engineering Failure Analysis, vol. 76, pp. 27-43, 2017.

[17] Y. C. Chen and L. W. Chen, "Effects of insulated rail joint on the wheel/rail contact stresses under the condition of partial slip," Wear, vol. 260, no. 11-12, pp. 1267-1273, 2006.

[18] C. Lu, I. J. Nieto, and J. M. J. Martínez-EsnaolaMelendez, "Fatigue prediction of rail welded joints," International Journal of Fatigue, vol. 113, pp. 78-87, 2018.

[19] Y. C. Chen and J. H. Kuang, "Contact stress variations near the insulated rail joints," Proceedings of the Institution of Mechanical Engineers, Part F: Journal of Rail and Rapid Transit, vol. 216, no. 4, pp. 265-273, 2002.

[20] N. K. Mandal, "FEA to assess plastic deformation of railhead material damage of insulated rail joints with fibreglass and nylon end posts," Wear, vol. 366-367, pp. 3-12, 2016.

[21] N. K. Mandal, "Ratchetting of railhead material of insulated rail joints (IRJs) with reference to endpost thickness," Engineering Failure Analysis, vol. 45, pp. 347-362, 2014.

[22] M. Wiest, E. Kassa, W. Daves, J. C. O. Nielsen, and H. Ossberger, "Assessment of methods for calculating contact pressure in wheel-rail/switch contact," Wear, vol. 265, no. 910, pp. 1439-1445, 2008.

[23] J. Li, J. Ding, Y. Niu et al., "Analysis of wheel and rail rolling contact theory of switch," Journal of Southwest Jiaotong University, vol. 54, no. 1, pp. 1-9, 2019, in Chinese.

[24] J. J. Kalker and K. L. Johnson, Three-Dimensional Elastic Bodies in Rolling Contact, Kluwer Academic Publishers, Delft, The Netherlands, 1990.

[25] W. M. Zhai, Vehicle-Track Coupling Dynamics, China Railway Publishing House, Beijing, China, 2nd edition, 2002.

[26] Z. S. Ren, Wheel/Rail Multi-Point Contacts and VehicleTurnout System Dynamic Interactions, Science Press, Beijing, China, (in Chinese), 2014.

[27] The Committee of Routine Turnout Main Parameters Handbook, Routine Turnout Main Parameters Handbook, Routine Turnout Main Parameters Handbook, China Railway Publishing House, Beijing, China, 2007, in Chinese.

[28] F.-S. Liu, Z.-P. Zeng, and W.-D. Shuaibu, "Stochastic analysis of nonlinear vehicle-track coupled dynamic system and its application in vehicle operation safety evaluation," Shock and Vibration, vol. 2019, pp. 1-23, 2019.

[29] J. A. Elkins and R. A. Allen, "Verification of a transit vehicle's curving behavior and projected wheel/rail wear performance," Journal of Dynamic Systems, Measurement, and Control, vol. 104, no. 3, pp. 247-255, 1982. 